\title{
EFEITOS DE PROCESSO DE SECAGEM E TEMPO DE ARMAZENAMENTO NA QUALIDADE TECNOLÓGICA DE TRIGO
}

\author{
Effects of drying process and storage time on technological quality of wheat
}

\author{
Janete Deliberali ${ }^{1}$, Maurício Oliveira ${ }^{1}$, Angelise Durigon ${ }^{2}$, \\ Alvaro Renato Guerra Dias ${ }^{3}$, Luiz Carlos Gutkoski ${ }^{4}$,Moacir Cardoso Elias ${ }^{3}$
}

\begin{abstract}
RESUMO
Neste trabalho, objetivou-se estudar a influência dos processos de secagem estacionário e intermitente e do tempo de armazenamento na qualidade tecnológica de grãos de trigo, cultivar Embrapa 16 colhidos com teor de água de 15\% e 19\%. Grãos de trigo (Triticum aestivum L) foram produzidos em lavoura comercial da Granja Bretanhas, Cooperativa Arrozeira Extremo Sul, no município de Jaguarão, RS. O experimento foi conduzido em delineamento inteiramente casualizado, utilizando dois teores de água de colheita (15\% e 19\%), dois processos de secagem (estacionário e intermitente) e quatro tempos de armazenamento. A secagem foi realizada até o teor de água de $13 \%$ e os grãos acondicionados em embalagens de algodão, em sistema de armazenamento convencional pelo período de 12 meses. Nos tempos zero, 4, 8 e 12 meses foram realizadas as análises de teor de água, peso hectolitro, cinzas, lipídios, acidez graxa, número de queda e alveografia. Os parâmetros mais efetivos para avaliar o efeito dos processos de secagem de trigo intermitente e estacionário em função do tempo de armazenamento foram peso do hectolitro, lipídios e acidez graxa indicando melhor qualidade tecnológica na secagem realizada em secador intermitente. O trigo, cultivar Embrapa 16, colhido seco na planta apresentou qualidade tecnológica inferior e menor conservabilidade ao armazenamento do que o colhido de forma antecipada e seco em secador intermitente.
\end{abstract}

Termos para indexação: Triticum aestivum, pós-colheita, número de queda, alveografia.

\section{ABSTRACT}

The objective of this work was to investigate the influence of stationary and intermittent drying process was well as storage time on the technological quality of wheat, cultivar Embrapa 16 harvested at 15\% and 19\% moisture content. Wheat grains (Triticum aestivum L) were produced in a commercial plantation at Granja Bretanhas, Cooperativa Arrozeira Extremo Sul, in Jaguarão, RS. The experiment was carried out in a completely randomized design, using two harvest moisture contents (15\% and 19\%), two drying processes (stationary and intermittent) and 4 storage times. Drying was performed up to $13 \%$ moisture content and the grains were kept in cotton packets, at conventional storage system for 12 months. Moisture content, hectoliter weight, ash, fat, fatty acid, falling number and alveography were evaluated at zero, 4,8 and 12 months. The results of hectoliter weight, fat, fatty acid, ash and falling number showed effective when evaluated the technological quality of wheat, cultivar Embrapa 16 harvested at 15\% and 19\% moisture content. Wheat harvest dry at the plant shows inferior technological quality and less conservability in storage as compared to preharvested wheat dried at intermittent dryer.

Index terms: Triticum aestivum, post-harvest, falling number, alveography.

(Recebido em 27 de junho de 2008 e aprovado em 16 de abril de 2009)

\section{INTRODUÇÃO}

A qualidade do grão de trigo pode ser definida como resultado da interação que a cultura sofre no campo, efeito das condições do solo, manejo da cultura, do cultivar, bem como das operações de colheita, armazenamento e moagem (Fleurat-Lessard, 2002; Edwards, 2004). Em condições inadequadas de secagem e armazenamento, o trigo pode sofrer alterações em suas propriedades físicas, químicas e reológicas reduzindo o valor comercial e a funcionalidade da farinha (Pomeranz, 1987).

Ao se considerar que o ar empregado é o ambiente, ou o movimentado artificialmente, Biagi et al. (2002) classificou a secagem de grãos de trigo em natural e artificial. $\mathrm{Na}$ secagem artificial os processos podem ser realizados em silos secadores, secagem intermitente, secagem contínua e seca-aeração. Na secagem artificial o excesso de água do grão é removido rapidamente até o limite conveniente, minimizando alterações metabólicas e danos

\footnotetext{
${ }^{1}$ Universidade Federal de Pelotas/UFPEL - Capão do Leão, RS

2Universidade de Passo Fundo/UPF - Passo Fundo, RS

${ }^{3}$ Universidade Federal de Pelotas/UFPEL - Faculdade de Agronomia Eliseu Maciel/FAEM - Departamento de Ciência e Tecnologia Agroindustrial/DCTA Capão do Leão, RS

${ }^{4}$ Universidade de Passo Fundo/UPF - Faculdade de Agronomia e Medicina Veterinária - Km 171 - BR 285 - São José - Cx. P. 611 - $99001-970$ - Passo

Fundo, RS - gutkoski@upf.br
} 
pela ação de fungos e insetos (Oliveira et al., 2010). A secagem de trigo, quando realizada com ar natural a temperatura ambiente e/ou artificial aquecido em baixas temperaturas, as alterações qualitativas do grão são mínimas, contribuindo para a manutenção da qualidade original do produto (Elias et al., 2007).

Em grãos de aveia com teor de água superior a $16 \%$, a secagem deve ser lenta e realizada de forma que a temperatura máxima na massa de grãos não ultrapasse $45^{\circ} \mathrm{C}$ para melhor manutenção da qualidade tecnológica dos produtos de moagem (Marini et al., 2007). Quando na secagem de grãos de trigo for empregada alta temperatura do ar, ocorre um aumento na velocidade do processo, porém com possibilidade de alterar a qualidade tecnológica das proteínas formadoras de glúten. $\mathrm{O}$ efeito da temperatura de secagem no teor de glúten de trigo foi estudado por Ragasits (1993). O teor de glúten apresentou redução em temperaturas superiores a $60^{\circ} \mathrm{C}$, sendo mais significativa aos $80^{\circ} \mathrm{C}$, e a quantificação ficou impossibilitada quando a temperatura atingiu $100^{\circ} \mathrm{C}$.

A qualidade dos grãos durante o armazenamento deve ser preservada ao máximo, tendo em vista a ocorrência de alterações enzimáticas e não enzimáticas, físicas, químicas e microbiológicas. Os principais aspectos a serem considerados são teor de água e temperatura de armazenamento, ocorrência de pragas e fungos, que danificam os grãos e alteram a qualidade tecnológica da farinha (Salunkhe, 1985; Guarienti et al., 2004). No armazenamento realizado em condições inadequadas, pode ocorrer a contaminação dos grãos por fungos que, além de consumirem nutrientes essenciais, reduzem a qualidade $\mathrm{e}$ produzem micotoxinas potencialmente deletérias à saúde humana e animal (Edwards, 2004; Koch et al., 2006).

Carneiro et al. (2005), estudando a influência da época de colheita, secagem artificial e período de armazenamento na qualidade de grãos de trigo comum e duro verificaram aumento significativo da atividade da enzima alfa-amilase, com o atraso da colheita. Com antecipação da colheita e da secagem não foi reduzida a qualidade dos grãos e, com a armazenagem, ocorreu aumento da força geral de glúten e redução na atividade amilolítica da farinha do trigo. A melhor qualidade da farinha de trigo armazenado por oito meses pode estar relacionada às modificações bioquímicas, com alteração da qualidade tecnológica do grão.

Neste trabalho, objetivou-se estudar a influência dos processos de secagem estacionário e intermitente $\mathrm{e}$ do período de armazenamento de doze meses na qualidade tecnológica de grãos de trigo, cultivar Embrapa 16 colhidos nos teores de água de $15 \%$ e $19 \%$.

\section{MATERIAL E MÉTODOS}

No trabalho, foram utilizados grãos de trigo (Triticum aestivum L), cultivar Embrapa 16, produzidos em solo de várzea, tipo planossolo, em lavoura comercial da Granja Bretanhas, Cooperativa Arrozeira Extremo Sul, localizada no município de Jaguarão, RS. Após a colheita, os grãos foram separados em amostras para serem submetidas aos testes de secagem e armazenamento realizados no Laboratório de Pós-Colheita, Industrialização e Qualidade de Grãos do Departamento de Ciência e Tecnologia Agroindustrial da Faculdade de Agronomia "Eliseu Maciel", na Universidade Federal de Pelotas.

$\mathrm{O}$ experimento foi conduzido em delineamento inteiramente casualizado, utilizando dois teores de água de colheita e dois processos de secagem, com análises, em triplicatas, realizadas nos tempos zero, 4,8 e 12 meses de armazenamento. A colheita foi realizada com automotriz, nos teores de água de $15 \%$ (colheita convencional) e de $19 \%$ (colheita antecipada). A pré-limpeza foi realizada em máquina piloto de ar e peneiras até valores inferiores a $1 \%$ de impurezas e ou matérias estranhas. Os grãos foram submetidos à secagem artificial pelos métodos estacionários, com temperatura do ar a $45^{\circ} \mathrm{C}$ e intermitente, com temperatura do ar a $65^{\circ} \mathrm{C}$ até atingirem $13 \%$ de água. Após a secagem, foram separadas amostras para a realização das avaliações no início do armazenamento e os grãos foram acondicionados em embalagens, em sistema de armazenagem convencional pelo período de 12 meses. No sistema convencional, os grãos de trigo foram armazenados em sacos de algodão, de $4 \mathrm{~kg}$, dispostos em pilhas, em condições atmosféricas não modificadas e com controle técnico operacional, constituído de avaliações mensais da infestação de insetos.

$\mathrm{O}$ teor de água foi determinado pelo método da estufa a $105 \pm 3^{\circ} \mathrm{C}$, com circulação natural de ar, por 24 horas, de acordo com as Regras de Análise de Sementes (Brasil, 1992), em triplicata e os resultados expressos em porcentagem e em base úmida. Para a determinação de peso hectolitro, foi empregada a balança marca Dalle Molle (Balanças Dalle Molle Ltda, Caxias do Sul, Brasil), sendo realizado de acordo com a metodologia descrita por Regras de Análise de Sementes (Brasil, 1992), em triplicata e os resultados expressos em $\mathrm{kg} \mathrm{hL}^{-1}$.

Os teores de lipídios e cinzas foram determinados de acordo com o procedimento descrito pela American Association of Cereal Chemists - AACC (1995), métodos número 30-20 e 08-01, respectivamente. Os resultados das análises realizadas foram expressos em porcentagem e em base seca. A acidez graxa foi determinada de acordo com o procedimento descrito pela AACC (1995), método número 58-15, após a 
extração dos lipídios em aparelho Soxleth e posterior titulação com $\mathrm{NaOH} 0,1 \mathrm{~N}$. As análises foram realizadas em triplicata e os resultados expressos em porcentagem.

As amostras de trigo foram moídas em moinho de laboratório Brabender, modelo Quadrumat Sênior, realizada de acordo com o método número 26-95 da AACC (1995). $\mathrm{Na}$ farinha, foi determinado o número de queda, realizado de acordo com a AACC (1995), método número 56-81B, pela utilização do aparelho Falling Number (Perten Instruments, Suíça), realizado em triplicata e os resultados expressos em segundos.

As características viscoelásticas da massa foram determinadas em alveógrafo Chopin, modelo MA 95 (Villeneuve-la-Garenne Cedex, França) utilizando o método $\mathrm{n}^{\circ}$ 54-30 da AACC (1995), por meio da pesagem de $250 \mathrm{~g}$ de farinha e volume de 129,4 mL de água, corrigido na base de $14 \%$ de teor de água. Os parâmetros obtidos nos alveogramas foram tenacidade (P), que mede a sobrepressão máxima exercida na expansão da massa $(\mathrm{mm})$; extensibilidade (L), que mede o comprimento da curva $(\mathrm{mm})$ e força geral do glúten (W x 10-4 J), que corresponde ao trabalho mecânico necessário para expandir a bolha até a ruptura.

Os resultados foram analisados pelo emprego da análise de variância (Anova) e nos modelos significativos pelo teste $\mathrm{F}$, realizadas as análises de regressão ou a comparação de médias pelo emprego do teste de Tukey em nível de $5 \%$ de probabilidade de erro. O processamento de dados e a análise estatística foram realizados com o uso do programa estatístico SAS Institute(1985) e os gráficos elaborados com o auxílio do programa estatístico Microsoft Excel $^{\circledR}$, no modo estatístico.

\section{RESULTADOS E DISCUSSÃO}

Na Tabela 1, estão apresentados os resultados de teor de água dos grãos de trigo, colhidos com dois teores de umidade, submetidos aos processos de secagem intermitente e estacionário e armazenados em sistema convencional pelo período de 12 meses.

O teor de água dos grãos variou significativamente tanto para processos de secagem quanto para período de armazenamento. Em todos os tratamentos o equilíbrio higroscópico dos grãos foi atingido após o quarto mês de armazenamento. A umidade, em todos os tratamentos, foi se alterando até atingir valores entre 13,05 e 13,49\%, demonstrando que nessa faixa situa-se o equilíbrio higroscópico do trigo nas condições de armazenamento estudado.

Quando a pressão de vapor do grão for maior do que a do ar circundante, ocorre o fenômeno de dessorção, havendo transferência de vapor de água para o ar. $\mathrm{O}$ contrário acontece quando a pressão de vapor do grão for menor do que a do ar circundante, havendo adsorção de água pelos grãos e, consequentemente, reumidecimento (Silva et al., 1995). O equilíbrio higroscópico é influenciado pela composição química do grão, integridade física, estado sanitário, gradientes termo hídricos e as operações de póscolheita, dentre os quais a secagem e o armazenamento são as mais importantes (Carneiro et al., 2005).

Na Figura 1A, estão apresentados os valores de peso hectolitro (PH) de grãos de trigo do cultivar Embrapa 16. A análise estatística mostrou diferenças significativas $(\mathrm{p}<0,05)$ para $\mathrm{PH}$, durante o período de armazenamento estudado, em função do processo de secagem e do tipo de colheita. Os modelos de regressão foram significativos nos quatro tratamentos estudados, sendo utilizados no ajuste os termos quadráticos, com coeficientes de determinação acima de 0,97 . Os maiores valores de $\mathrm{PH}$ foram verificados nos grãos secos em secagem intermitente e a colheita realizada de forma antecipada $(\mathrm{AI})$. Na colheita antecipada e secagem estacionária (AE) os valores de $\mathrm{PH}$ foram

Tabela 1 - Teor de água de grãos de trigo, cultivar Embrapa 16, submetidos aos tratamentos de colheita antecipada e secagem intermitente (AI), colheita antecipada e secagem estacionária (AE), colheita convencional e secagem intermitente (CI), colheita convencional e secagem estacionária (CE) e armazenados em sistema convencional por 12 meses ${ }^{1}$.

\begin{tabular}{lcccc}
\hline \multicolumn{5}{c}{ Período de armazenamento (meses) } \\
\hline Tratamento & 0 & 4 & 8 & 12 \\
\hline AI & C $11,58 \mathrm{c}$ & B $12,19 \mathrm{~b}$ & A $13,14 \mathrm{a}$ & A $13,06 \mathrm{a}$ \\
$\mathrm{AE}$ & $\mathrm{C} 11,50 \mathrm{c}$ & B $12,30 \mathrm{~b}$ & A $13,03 \mathrm{a}$ & A $13,05 \mathrm{a}$ \\
$\mathrm{CI}$ & $\mathrm{A} 12,99 \mathrm{ab}$ & B $12,29 \mathrm{~b}$ & $\mathrm{~A} 13,21 \mathrm{a}$ & A $13,39 \mathrm{a}$ \\
$\mathrm{CE}$ & $\mathrm{AB} 12,57 \mathrm{~b}$ & A $12,68 \mathrm{~b}$ & A $13,40 \mathrm{a}$ & A $13,49 \mathrm{a}$ \\
\hline
\end{tabular}

${ }^{1}$ Médias não seguidas de mesma letra, minúscula na horizontal e maiúscula na vertical, diferem entre si pelo teste de Tukey em nível de $5 \%$ de probabilidade de erro. 
inferiores aos verificados no tratamento AI indicando que o processo de secagem afetou o $\mathrm{PH}$ dos grãos de trigo, durante o período de armazenamento estudado. Na colheita convencional, as maiores perdas de $\mathrm{PH}$ foram verificadas quando realizada a secagem estacionária. Ao longo do armazenamento foi verificado uma redução do PH em todos os tratamentos estudados, sendo mais significativa para colheita convencional e secagem estacionária (CE).

O peso hectolitro é um indicador de qualidade que se correlaciona com taxa de extração de farinha, sendo mais elevada quanto maior o valor obtido. Ao longo do armazenamento ocorre redução de $\mathrm{PH}$, em virtude do consumo de componentes orgânicos dos próprios grãos (Fleurat-Lessard, 2002). A redução do PH durante a armazenagem pode ser atribuída a efeitos do tipo de colheita, processo de secagem e teor de água final de armazenamento e não a danos mecânicos dos grãos (Marini et al., 2005). Os valores de PH refletem as perdas quantitativas totais, resultantes dos processos de deterioração dos grãos, em razão do seu metabolismo intrínseco, à atividade microbiana e a de pragas associadas. As menores variações de $\mathrm{PH}$ observadas na secagem intermitente e em colheita antecipada correspondem aos melhores parâmetros conservativos da massa de grãos durante o armazenamento.

A análise estatística mostrou diferenças significativas $(\mathrm{p}<0,05)$ para os teores de lipídios, durante o período de armazenamento estudado, em função do processo de secagem e do teor de água de colheita (Figura 1B). Os modelos de regressão foram significativos nos quatro
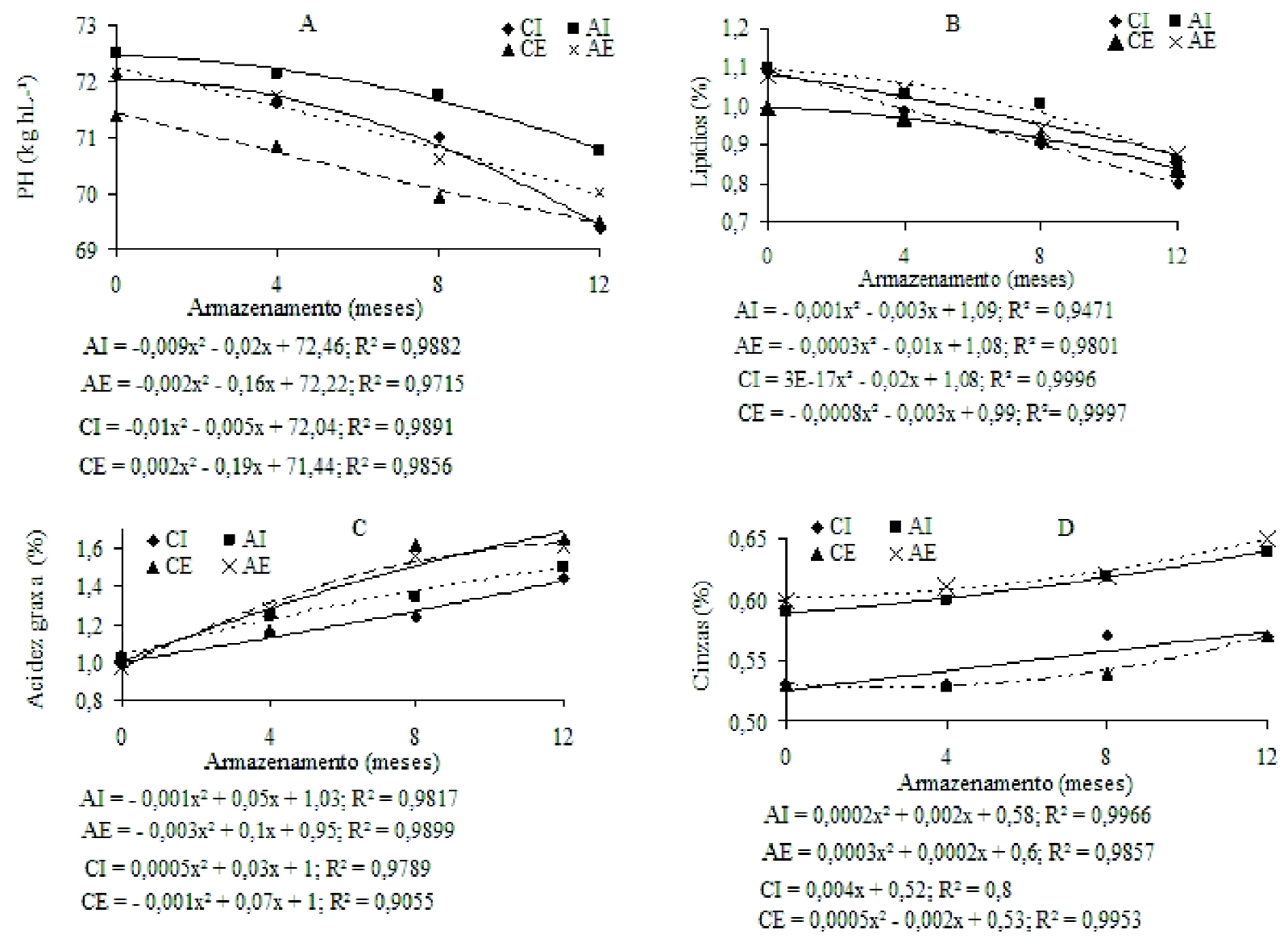

Figura 1 - Equações de regressão para as análises de peso hectolitro (A), lipídios (B), acidez graxa (C) e cinzas (D) de grãos de trigo, cultivar Embrapa 16, submetidos aos tratamentos de colheita antecipada e secagem intermitente (AI), colheita antecipada e secagem estacionária (AE), colheita convencional e secagem intermitente (CI), colheita convencional e secagem estacionária $(\mathrm{CE})$ e armazenados em sistema convencional por 12 meses. 
tratamentos estudados, sendo utilizados no ajuste os termos quadráticos, com coeficientes de determinação acima de 0,94. No início do armazenamento, os valores de lipídios não variaram significativamente entre si. Ao longo do armazenamento, ocorreu redução no teor de lipídios em todos os tratamentos estudados. Na colheita antecipada, a redução foi menor quando comparada com a convencional, provavelmente por terem ocorrido menores danos metabólicos nos grãos. Os menores valores de lipídios foram verificados em colheita convencional e secagem estacionária.

Os lipídios presentes nos grãos estão na forma de triglicerídios e a sua hidrólise para ácidos graxos livres e glicerol durante o armazenamento é resultante da respiração do próprio grão, processos de oxidação, ação de enzimas, entre outros fatores (Fleurat-Lessard, 2002). Esse é o constituinte químico do grão mais suscetível à deterioração e o grau de degradação é indicador de conservabilidade, durante o período de armazenamento (Bhattacharya \& Raha, 2002). Os resultados obtidos no presente trabalho estão em acordo com Rupollo et al. (2004) e Marini et al. (2005), os quais também verificaram diminuição no teor de lipídios com o aumento do tempo de armazenamento em grãos de aveia. Em aveia, pela presença de maior quantidade de lipídios e a grande atividade lipolítica, a variação deste constituinte é mais efetiva o que facilita visualizar as alterações metabólicas do grão em função das operações de pós-colheita empregadas (Gutkoski \& El-Dash, 1999).

A redução no teor de lipídios e o aumento no teor de ácidos graxos livres estão diretamente correlacionados com a velocidade e intensidade do processo deteriorativo dos grãos. A avaliação desses indicadores constitui em eficiente parâmetro para o monitoramento da conservabilidade de grãos durante o armazenamento (Salunkhe, 1985).

A análise estatística dos resultados de acidez graxa mostrou diferenças significativas $(\mathrm{p}<0,05)$ durante o período de armazenamento estudado, em função do processo de secagem e do tipo de colheita dos grãos de trigo. Os modelos de regressão foram significativos nos quatro tratamentos estudados, sendo utilizado no ajuste os termos quadráticos, com coeficientes de determinação acima de 0,90 (Figura 1C). No processo de secagem intermitente, os valores de acidez graxa foram significativamente inferiores quando comparados com a secagem estacionária. Quanto ao tipo de colheita, os grãos de trigo mostraram menor conservabilidade na convencional, sendo que os maiores valores de acidez graxa após o período de 12 meses de armazenamento ocorreram em colheita convencional e secagem estacionária (CE).
O tempo prolongado de contato do ar com os grãos, característico do sistema estacionário de secagem pode provocar mais dano térmico do que o intermitente empregado, predispondo o grão a ação das enzimas lipases e o consequente aumento da acidez graxa (Marini et al., 2007). Os resultados do presente trabalho estão em acordo com os relatados por Bhattacharya \& Raha (2002) que verificaram uma diminuição no conteúdo de lipídios com simultâneo aumento da acidez graxa, durante o período de armazenamento de grãos de milho e soja.

Para o teor de cinzas foi verificado efeito significativo do tipo de colheita, sendo verificado maiores valores na colheita antecipada com o aumento do tempo de armazenamento, porém sem diferenças significativas entre os processos de secagem estudados. $\mathrm{O}$ aumento nos valores de cinzas com os tempos de armazenamento foram decorrentes do consumo de componentes orgânicos pelo metabolismo dos grãos (Figura 1D). O conteúdo de cinzas no grão e, consequentemente, na farinha, é influenciado por fatores genéticos, disponibilidade dos nutrientes, teor de matéria orgânica, estádio de maturação do grão na colheita, condicionamento e grau de extração da farinha durante a moagem (Salunkhe, 1985).

O aumento do teor de cinzas durante o armazenamento implica em degradação da fração orgânica. Dentre os constituintes da farinha de trigo, o conteúdo de cinzas é a fração que apresenta as menores variações em conteúdo total, durante o armazenamento. A atividade metabólica dos grãos e dos microrganismos associados consome materiais orgânicos, produzindo gás carbônico, água, calor e outros produtos, podendo alterar a quantidade de cinzas presentes no grão. Dessa forma, a determinação do teor de cinzas assume valores, proporcionalmente, maiores na medida em que a matéria orgânica é consumida (Bhattacharya \& Raha, 2002).

A análise estatística mostrou diferenças significativas $(\mathrm{p}<0,05)$ para força geral do glúten durante o período de armazenamento estudado, em função do processo de secagem e do tipo de colheita dos grãos de trigo. Os modelos de regressão foram significativos em três tratamentos estudados, sendo utilizados no ajuste os termos quadráticos. Os valores de $\mathrm{W}$ no cultivar estudado foram baixos, característicos de trigo brando (Brasil, 2001), sendo verificado um aumento até o oitavo mês de armazenamento e redução aos 12 meses de armazenamento (Figura 2A). Gutkoski et al. (2008) estudaram a variação da qualidade tecnológica da farinha de trigo com a maturação de grãos de trigo, durante 60 dias de armazenamento e encontraram que os genótipos BRS 179 e Fundacep 51 passaram das 
classes brando para pão, enquanto o Rubi de pão para melhorador. Com a maturação ocorreu um ganho tecnológico e comercial, sugerindo que o trigo não deva ser comercializado antes deste período de armazenamento, pois o mesmo apresenta melhoria na classificação comercial. Porém, conforme os resultados do presente trabalho, a melhoria ocorreu somente até o oitavo mês, reduzindo após esse período, provavelmente decorrente da degradação de constituintes do grão, como lipídios e acidez graxa.

A alveografia é um teste reológico empregado para avaliar as características viscoelásticas da massa de farinha de trigo e a expressão força de glúten (W) é utilizada para designar a maior ou menor capacidade de uma farinha sofrer um tratamento mecânico ao ser misturada com água. Também é associada à maior ou menor capacidade de absorção de água pelas proteínas formadoras de glúten, que combinadas à capacidade de retenção do gás carbônico resulta em pão de volume aceitável, textura interna sedosa e granulometria aberta (Dobraszczyk \& Morgenstern, 2003). A secagem é um fator operacional que pode modificar as características do glúten e quando realizada em temperaturas demasiadamente altas provoca a desnaturação (Dellavale et al., 2006). Ragasits (1993) estudando o efeito da secagem sobre a qualidade do trigo observou que em temperaturas de secagem acima de $60^{\circ} \mathrm{C}$ ocorreu redução no teor de glúten. Neste trabalho, as temperaturas estudadas não afetaram os resultados de alveografia, indicando ser inferiores a necessária para a desnaturação do glúten.

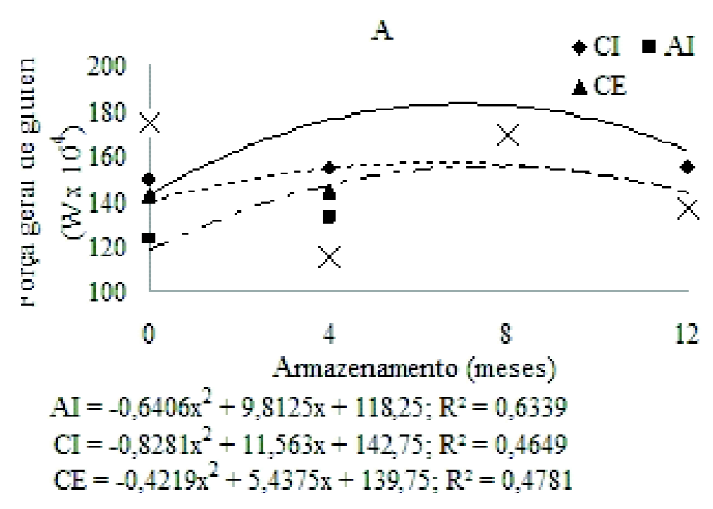

Os modelos de regressão para número de queda foram significativos em todos os tratamentos estudados, sendo verificado aumento com o tempo de armazenamento do trigo (Figura 2B). O melhor ajuste foi verificado na colheita convencional e secagem estacionária, com coeficiente de determinação de 0,99 . Os maiores valores de número de queda foram verificados na colheita antecipada, independentemente do processo de secagem empregado.

O número de queda permite estimar a capacidade de fermentação da massa de determinada farinha, pois quanto maior o valor encontrado, menor a atividade amilásica, o que dificulta o processo industrial. A quantidade de enzima presente nas farinhas tem uma influência direta sobre a qualidade do pão produzido. $\mathrm{O}$ valor do número de queda apresenta relação inversa com a atividade da alfa-amilase, ou seja, quanto maior o valor da atividade da alfa-amilase menor o valor do número de queda (Guarienti, 1996).

Neste estudo, os valores de número de queda para colheita antecipada foram maiores e apresentaram aumento com o período de armazenamento, o que exige a adição de maiores quantidades de enzimas amilolíticas para a utilização da farinha em produtos de panificação. Porém, elevado valor de número de queda não é um problema de difícil solução, pois normalmente a formulação dos reforçadores ou melhoradores utilizados em panificação apresenta enzima alfa-amilase fúngica, com a finalidade de correção dessa deficiência na farinha de trigo (Guarienti, 1996). Os resultados deste trabalho estão em acordo com

Figura 2 - Equações de regressão para as análises de força geral do glúten (A) e número de queda (B) de grãos de trigo, cultivar Embrapa 16, submetidos aos tratamentos de colheita antecipada e secagem intermitente (AI), colheita antecipada e secagem estacionária (AE), colheita convencional e secagem intermitente (CI), colheita convencional e secagem estacionária (CE) e armazenados em sistema convencional por 12 meses. 
Carneiro et al. (2005), que verificaram elevação dos valores de número de queda com o aumento do período de armazenamento de grãos de trigo comum e duro.

\section{CONCLUSÕES}

Os parâmetros mais efetivos para avaliar o efeito dos processos de secagem de trigo intermitente e estacionário em função do tempo de armazenamento foram peso do hectolitro, lipídios e acidez graxa, indicando melhor qualidade tecnológica na secagem realizada em secador intermitente. Para tipo de colheita de trigo em função do tempo de armazenamento os parâmetros mais efetivos foram teor de cinzas e número de queda indicando melhor qualidade tecnológica para a colheita realizada de forma antecipada. As temperaturas empregadas na secagem não afetaram a qualidade do glúten, avaliado pela análise de alveografia. O trigo, cultivar Embrapa 16, colhido seco na planta apresentou qualidade tecnológica inferior e menor conservabilidade ao armazenamento do que o colhido de forma antecipada e seco em secador intermitente.

\section{AGRADECIMENTOS}

À CAPES e ao CNPq, pelas bolsas; ao laboratório de Qualidade Industrial de Trigo da Embrapa Trigo, Passo Fundo, RS, pela realização de análises reológicas.

\section{REFERÊNCIAS BIBLIOGRÁFICAS}

AMERICAN ASSOCIATION OF CEREAL CHEMISTS. Approved methods of the American Association of Cereal Chemists. 9.ed. Saint Paul, 1995. v.2.

BHATTACHARYA, K.; RAHA, S. Deteriorative changes of maize, groundnut and soybean seeds by fungi in storage. Mycopathologia, Dordrecht, v.155, n.3, p.135$141,2002$.

BIAGI, J.D.; BERTOL, R.; CARNEIRO, M.C. Secagem de grãos para unidades centrais de armazenamento. In: LORINI, I.; MIIKE, L.H.; SCUSSEL, V.M. Armazenagem de grãos. Campinas: Instituto Bio Geneziz, 2002. cap.5.2, p.289-308.

BRASIL. Ministério da Agricultura, Pecuária e Abastecimento. Instrução Normativa SARC n. 7, de 15 de agosto de 2001. Aprova o regulamento técnico de identidade e qualidade do trigo. Diário Oficial da República Federativa do Brasil. Brasília, 21 ago. 2001.
BRASIL. Ministério da Agricultura, do Abastecimento e da Reforma Agrária. Secretaria de Defesa Agropecuária. Regras para análise de sementes. Brasília, 1992. 365p.

CARNEIRO, L.M.T.A.; BIAGI, J.D.; FREITAS, J.G. de; CARNEIRO, M.C.; FELÍCIO, J.C. Diferentes épocas de colheita, secagem e armazenamento na qualidade de grãos de trigo comum e duro. Bragantia, Campinas, v.64, n.1, p.127-137, 2005.

DOBRASZCZYK, B.J.; MORGENSTERN, M.P. Rheology and the breadmaking process. Journal of Cereal Science, New York, v.38, n.2, p.229-245, 2003.

EDWARDS, S.G. Influence of agricultural practices on fusarium infection of cereals and subsequent contamination of grain by trichothecene mycotoxins. Toxixology Letters, Washington, v.153, n.1, p.29-35, 2004.

ELIAS, M.C.; GUERRA, R.A.; ELIAS, S.A.A.; ANTUNES, P.L. Operações de pré-armazenamento, armazenamento e conservação de grãos. In: ELIAS, M.C. (Ed.). Pós-colheita de arroz: secagem, armazenamento e qualidade. Pelotas: UFPel, 2007. p.147-244.

FLEURAT-LESSARD, F. Qualitative reasoning and integrated management of the quality of stored grain: a promising new approach. Journal of Stored Products Research, Amsterdam, v.38, p.191-218, 2002.

GUARIENTI, E.M. Qualidade industrial de trigo. Passo Fundo: Embrapa Trigo, 1996. 36p.

GUARIENTI, E.M.; CIACCO, C.F.; CUNHA, G.R da; DEL DUCA, L. de J.A.; CAMARGO, M.C.M. de O. Influência das temperaturas mínima e máxima em características de qualidade industrial e em rendimentos de grãos de trigo. Ciência e Tecnologia de Alimentos, Campinas, v.24, n.4, p.505-515, 2004.

GUTKOSKI, L.C.; DURIGON, A.; MAZZUTTI, S.; SILVA, A.C.T.; ELIAS, M.C. Efeito do período de maturação de grãos nas propriedades físicas e reológicas de trigo. Ciência e Tecnologia de Alimentos, Campinas, v.28, n.4, p.1-12, 2008.

GUTKOSKI, L.C.; EL-DASH, A.A. Efeito do cozimento por extrusão na estabilidade oxidativa de produtos de moagem de aveia. Pesquisa Agropecuária Brasileira, Brasília, v.34, n.1, p.119-127, 1999. 
KOCH, H.J.; PRINGAS, C.; MAERLAENDER, B. Evaluation of environmental and management effects on Fusarium head blight infection and deoxynivalenol concentration in the grain of winter wheat. European Journal of Agronomy, Milano, v.24, n.2, p.357-366, 2006.

MARINI, L.J.; GUTKOSKI, L.C.; ELIAS, M.C.; MEZZOMO, N. Efeito da secagem intermitente na estabilidade de grãos de aveia. Brazilian Journal of Food Technology, Campinas, v.8, n.3, p.260-267, 2005.

MARINI, L.J.; GUTKOSKI, L.C.; ELIAS, M.C.; SANTIN, J.A. Qualidade de grãos de aveia sob secagem intermitente em altas temperaturas. Ciência Rural, Santa Maria, v.37, n.5, p.1268-1273, 2007.

OLIVEIRA, L. da C.; GUTKOSKI, L. C.; ELIAS, M. C.; MAZUTTI, S.; AOSANI, E.; ROCHA, J. C. da. Efeito da temperatura de secagem na qualidade de grãos de aveia branca. Ciência e Agrotecnologia, Lavras, v. 34, n. 2, p. 313-319, mar./abr., 2010.
POMERANZ, Y. Modern cereal science and technology. New York: VHC, 1987. 486p.

RAGASITS, I. Effect of driyng on the baking quality of wheat. Cereal Research Communications, Szeged, v.21, n.1, p.87-92, 1993.

RUPOLLO, G.; GUTKOSKI, L.C.; MARINI, L.; ELIAS, M.C. Sistemas de armazenamento hermético e convencional na conservabilidade de grãos de aveia. Ciência Rural, Santa Maria, v.34, n.6, p.1715-1722, 2004.

SALUNKHE, D.K. Nature of postharvest losses. In: Postharvest biotechnology of cereals. Boca Raton: CRC, 1985. p.9-22.

SILVA, J. de S.; AFONSO, A.D.L.; LACERDA FILHO, A.F.de. Secagem e armazenagem de produtos agrícolas. In: SILVA, J. de S. (Ed.). Pré-processamento de produtos agrícolas. Juiz de Fora: Instituto Maria, 1995. p.395-462.

STATISTICAL ANALYSIS SYSTEM INSTITUTE. User's guide: statistics. Cary, 1985. 956p. 